\title{
ONE-DIMENSIONAL HYDROGEN-BONDED N-H...O IN THE HYBRID PHOSPHATE: HIRSHFELD SURFACE ANALYSIS AND DFT QUANTUM CHEMICAL CALCULATIONS
}

\author{
Abdellatif Rafik ${ }^{1}{ }^{凶}$, Hafid Zouihri ${ }^{2}$, Taoufiq Guedira ${ }^{1}$
}

https://doi.org/10.23939/chcht15.03.359

\begin{abstract}
In the present work the 3D-supramolecular network is stabilized by $\mathrm{N}-\mathrm{H} . . . \mathrm{O}$ and $\mathrm{O}-\mathrm{H} . . . \mathrm{O}$ hydrogen bonds, by $\mathrm{O} \ldots \mathrm{N}$ interactions involving the organic cation and inorganic anion as checked by Hirshfeld surface analysis. The van der Waals contacts play a key role in the consolidation of the packing of 4-chloro-2-methylanilinium dihydrogenphosphate[4-CMDHP] structure. In order to support experimental results, density functional theory calculations have been performed using B3LYP functional with 3-21 $\mathrm{G}$ basis set. All of the obtained theoretical results are in a perfect agreement with the experimental ones. Furthermore, nonlinear optical behavior of 4-CMDHP has been investigated by determining the Hirshfeld surface, density of states and HOMO-LUMO energy gap using the same basis set. Finally, the molecular electrostatic potential surface of 4-CMDHP molecule was simulated and discussed.
\end{abstract}

Keywords: band gap, fingerprint plots, Hirshfeld surface, hybrid.

\section{Introduction}

Hybrid organic-inorganic materials are materials prepared by combining organic and inorganic building blocks. They are attracting increasing interest as a creative alternative for obtaining new materials with tailored structures and properties $[1,2]$. Due to their strength, as well directional nature (compared with other intermolecular non-covalent interactions), hydrogen bonds are normally used as a tool in designing the structure of the organic crystals [3]. Crystal engineering or the design

\footnotetext{
${ }^{1}$ Laboratory of Organic, Inorganic Chemistry, Electrochemistry and Environment, Faculty of Science, University of Ibn Tofail, B.P. 133, 14000 Kenitra, Morocco

${ }^{2}$ Laboratory of Chemistry of Materials and Biotechnology of Natural Products, University Moulay Ismail, Faculty of Sciences, Meknes, Morocco

凶abdellatif.rafik@uit.ac.ma

(c) Rafik A., Zouhri H., Guedira T., 2021
}

of organic crystals with the specific physical and chemical properties continues to elicit intense interest. This new subject encompasses a wide variety of research activity ranging from the understanding of crystal packing in organic and semi organic crystals to the design of open network structures. This structure extension property through non-covalent interactions was recognized as a possible tool for promoting crystallization [4]. It is known that co-crystals are crucial for the production of pharmaceutical compound. The most widely used application is in drug development and more specifically, the formation, design and implementation of active pharmaceutical ingredients [5].

Hence, in the present work, we report the hybrid structure, density functional theory (DFT) computations of 4-CMDHP Hirshfeld surface analysis, fingerprint plots, excitation energies, and Mulliken population analysis.

\section{Experimental}

\subsection{Quantum Chemical Calculations}

Recently, the quantum chemical calculations were performed by density functional theory (DFT) based on B3LYP/3-21G, PBEPBE/3-21G, MP2/3-21G, HF/3$21 \mathrm{G}$ basis sets approximation in the GAUSSIAN $03 \mathrm{~W}$ [6]. In this work, the theoretical results were visualized using the Gauss-View 5.0 visualization program [7]. The electrostatic potential surface and electronic properties were being recognized by DFT approach. Optimizations of the most stable conformers of 4-CMDHP were performed applying the B3LYP method in combination with the standard split-valence basis sets $3-21 \mathrm{G}$, for the prediction of electronic transitions.

\subsection{Hirshfeld Surface}

Hirshfeld surfaces and their associated twodimensional (2D) fingerprint plots [8] were plotted using CrystalExplorer 3.0 software [9]. The normalized contact 
distance $\left(d_{\text {norm }}\right)$, based on $d_{e}$ (distance from a point on the surface to the nearest nucleus outside the surface) and $d_{i}$ (distance from a point on the surface to the nearest nucleus inside the surface), was calculated via the Eq. (1):

$$
d_{\text {norm }}=\frac{d_{i}-r_{i}^{v d W}}{r_{i}^{v d W}}+\frac{d_{e}-r_{e}^{v d W}}{r_{e}^{v d W}}
$$

where $r_{i}^{v d W}$ and $r_{e}^{v d W}$ are the van der Waals radii of the atom that lies inside and outside the surface of Hirshfeld, respectively, $\AA$.

The Hirshfeld surface of the title compound. In this latter a color gradient is used, which varies from red (distances shorter than the sum of $v d W$ radii with negative $d_{\text {norm }}$ value) through white (represents the contact around $v d W$ separation with a $d_{\text {norm }}$ value of zero) to blue (distance longer than the sum of $v d W$ radii with positive $d_{\text {norm }}$ value).

The breakdown of 2D fingerprint plots was used for decoding and quantifying intermolecular interactions in the crystal lattice. The fingerprint plots can be decomposed to highlight particular atom pair close contacts [11], which overlap in the full fingerprint. The surfaces were mapped over a fixed colour scale from -0.720 (red) to $1.201 \AA$ (blue). The $2 \mathrm{D}$ fingerprint plots were displayed by using the translated $0.7-2.8 \AA$ range, including reciprocal contacts. ESP on 0.008 a.u. isosurfaces were calculated at the HF/6-31G level by using Tonto program $[12,13]$ integrated into CrystalExplorer.

\section{Results and Discussion}

\subsection{Description of Crystal Structure}

The ORTEP view of the title compound is shown in Fig. 1. The single crystal X-ray analysis shows that the molecules crystallize in the monoclinic system having chiral P $2 / 1$ space group with $Z=4$. The cell parameters were found to be $a=16.603 \AA, b=8.339 \AA, c=7.903 \AA$ and $V=1062.79(2) \AA^{3}$. The obtained crystallographic data are in a good agreement with values reported in the literature. The asymmetric unit of 4-CMDHP was found to contain $\mathrm{C}_{7} \mathrm{H}_{9} \mathrm{ClN}^{+} . \mathrm{H}_{2} \mathrm{PO}_{4}{ }^{-}$as $1: 1$ ratio of chloro-2methylanilinium cation and dihydrogen phosphate anion. The cation in general position and the phosphorus atoms exhibit a slightly distorted tetrahedral geometry. The atomic arrangement of this compound is built up by dimers with the $\left(\mathrm{H}_{2} \mathrm{PO}_{4}{ }^{-}\right)$formula. Each dimer aggregates with organic molecules, leading to the open framework architecture through hydrogen bond interactions. The structure in projection on the $(a, b)$ plane shows one type of column constructed by anions and cations running along the $c$ axis, formed by four $\mathrm{H}_{2} \mathrm{PO}_{4}{ }^{-}$and eight
$\left[\mathrm{C}_{7} \mathrm{H}_{9} \mathrm{ClN}^{+}\right]$(Fig. 2). The projection along $b$ also shows one type of columns formed by the same number of groups found in $(a, b)$ projection.

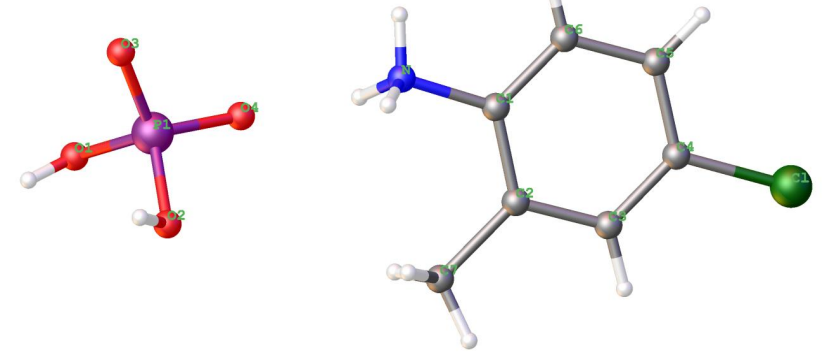

Fig. 1. The ORTEP representation of the asymmetric unit of the title compound shows one independent dihydrogen phosphate $\mathrm{H}_{2} \mathrm{PO}_{4}{ }^{-}$anion (left) and one 4-chloro-2methylanilinium $\mathrm{C}_{7} \mathrm{H}_{9} \mathrm{ClN}^{+}$cation (right). Displacement ellipsoids are drawn at the $50 \%$ probability level

In the chain organization of $\mathrm{H}_{2} \mathrm{PO}_{4}{ }^{-}$entity, it is worth noticing that the $\mathrm{O} \ldots \mathrm{O}$ distances involved in hydrogen bonds (2.540-2.817 $\AA$ ) are of the same magnitude than the $\mathrm{O}-\mathrm{O}$ edges in the $\mathrm{PO}_{4}$ tetrahedron $(2.430-2.540 \AA)$. The strength of $\mathrm{O}-\mathrm{H}$... O hydrogen bonds and the shortest $\mathrm{P}-\mathrm{P}$ distance $(4.375 \AA)$ between phosphorus atoms in each layer are in favor of the general formation of dihydrogen phosphate polyanions in the crystal structure, and not of the individualization of $\mathrm{HPO}_{4}{ }^{2-}$ groups. This polymeric structure is in accordance with what has been observed in other crystal structures (Fig. 2).

An examination of the organic moiety geometrical features shows that the bond length values of $\mathrm{C} 2-\mathrm{C} 3$

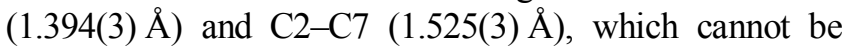
considered as double bonds, are longer than $\mathrm{C} 3-\mathrm{C} 4$

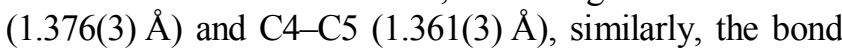
length values of $\mathrm{Cl}-\mathrm{N} \quad(1.450(2) \AA$ and $\mathrm{C} 4-\mathrm{Cl}$ $(1.733(2) \AA)$. Furthermore, the organic molecule is protonated in the acidic solution. The bonding of the $\mathrm{H}$ atom to the ring $\mathrm{N}$ atom gives an ion for which an additional resonance structure can be written as depicted below.

\subsection{Hirshfeld Surface Analysis}

The Hirshfeld surface $[14,15]$ is a fundamental access for investigating intermolecular interactions. All the molecular interactions revolving in the crystal packing are quantified, and the pie chart of molecular interactions is displayed in Fig. 3. The Hirshfeld surface around a molecule is indicated by points where the connection to the electron density from the molecule is identical to the influence from all other molecules. The normalized contact distance $d_{n o r m}$ is based on both $d_{e}$ and $d_{i}$, and the 
radii of the atom facilitate identification of the areas of specific intermolecular interactions [16, 17]. On behalf of every value on the isosurface, two distances are well defined, such as $d_{e}$, the distance from the point to the adjacent nucleus external to the surface and $d_{i}$, the distance to the adjacent nucleus internal to the surface.
The value of the $d_{\text {norm }}$ is negative or positive when intermolecular contacts are shorter or longer. Because of the symmetry between $d_{e}$ and $d_{i}$ in the appearance of $d_{\text {norm }}$, where two Hirshfeld surfaces touch, both will display a red spot identical in color intensity as well as size and shape.

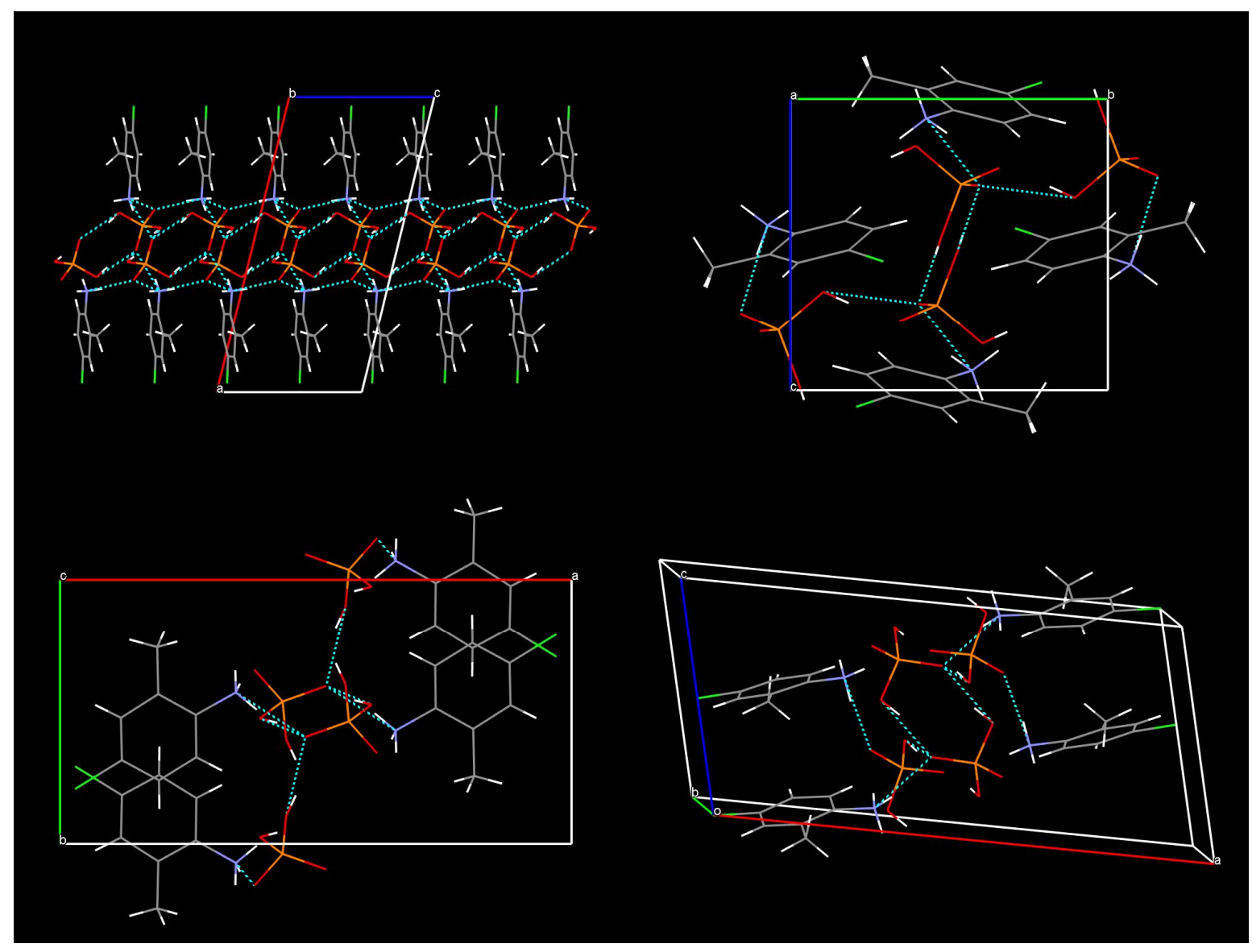

Fig. 2. A packing diagram for the title compound

The combination of $d_{e}$ and $d_{i}$ in the form of a 2D fingerprint plot provides an immediate of intermolecular interactions in the crystal. Graphical plots of the molecular Hirshfeld surfaces were mapped with $d_{\text {norm }}$ using a redwhite-blue color system. The red indicates less distance interaction, white is comparatively long distance around the surface, and blue represents longer interactions. Moreover, further colored properties (curvedness, Fig. 3(f)) based on the local curvature of the surface can be specified. Curvedness is the evaluation of "shape," while areas of sharp curvature possess a high curvedness and tend to divide the surface into patches associated with contacts between neighboring molecules. The analysis of 4-CMDHP reveals that the $\mathrm{O}-\mathrm{H} \cdots \mathrm{H}$ interaction possesses both of the donor and acceptor behaviors. This dual behavior can be explained from the observation of bright red spots, assigned to the short $\mathrm{H} \cdots \mathrm{O}$ and $\mathrm{O} \cdots \mathrm{H}$ contacts, on the $d_{\text {norm }}$ Hirshfeld surface, respectively [16]. The strong $\mathrm{O} \cdots \mathrm{H} / \mathrm{H} \cdots \mathrm{O}$ intermolecular interactions with a contribution of $35.7 \%$, appear as two distinct spikes in the 2D fingerprint plot (Fig. 4). The spikes on both sides are $\mathrm{Cl} \cdots \mathrm{H}$ interactions, with a contribution of $27.7 \%$. Two spikes in the middle represent the $\mathrm{H} \cdots \mathrm{H}$ interactions, with a contribution of $17.0 \%$ and H...C/C...H with contribution of $10.9 \%$ (Fig. 5). Hydrogen-bond donors and acceptors are shown as gray and black regions around the atoms corresponding to positive and negative potentials, respectively (Fig. 6b).

In summary, the Hirshfeld surface analysis and twodimensional fingerprint plots reveal that the molecular packing in the title compound is dominated by intermolecular van der Waals interactions between neighboring $\mathrm{H}$ atoms, as well as by $\mathrm{N}-\mathrm{H}$... O interactions. 


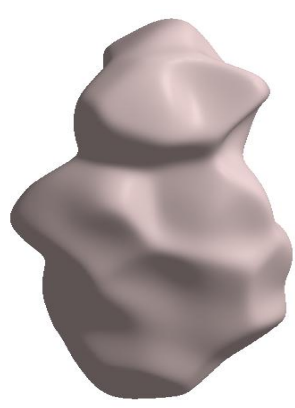

a)

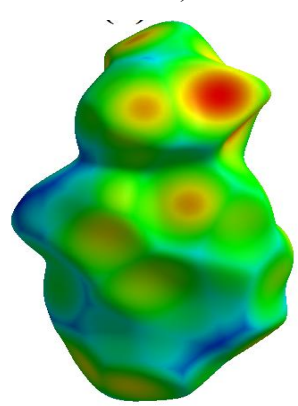

c)

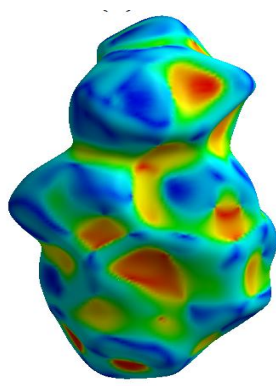

e)

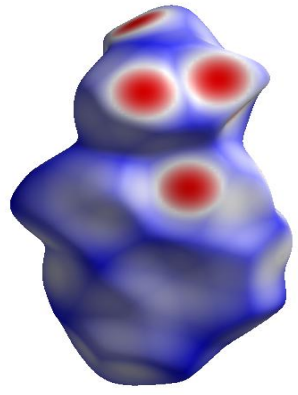

b)

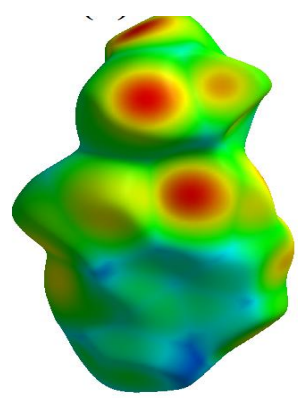

d)

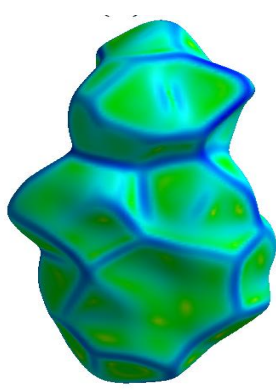

f)

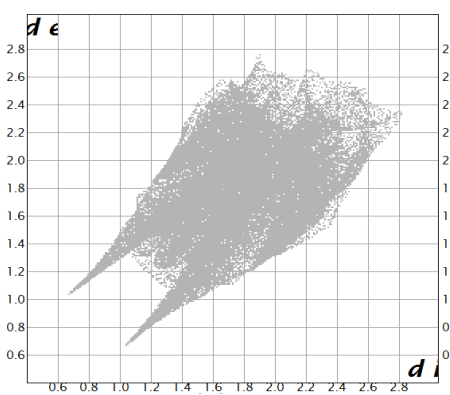

a)

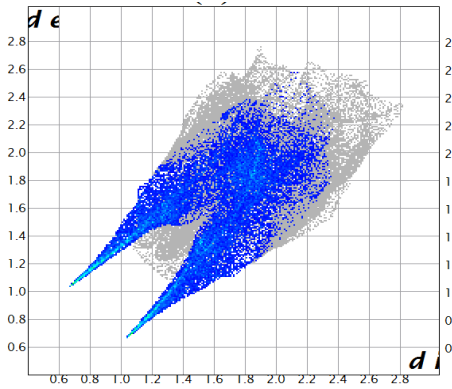

c)

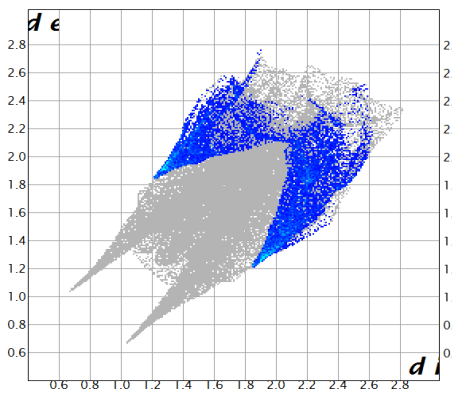

e)

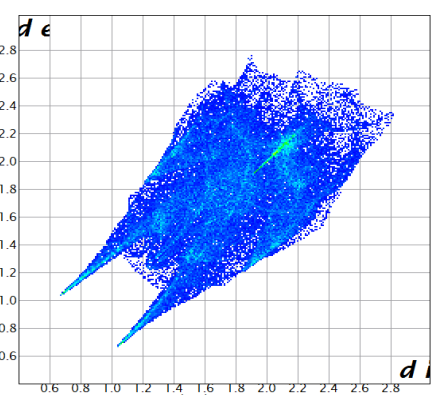

b)

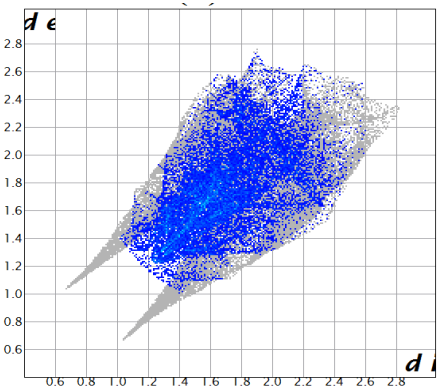

d)

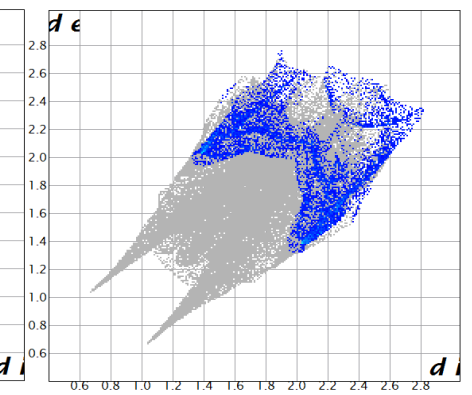

f)
Fig. 3. Hirshfeld surfaces mapped with none (a), $d_{\text {norm }}(\mathrm{b}), d_{e}(\mathrm{c}), d_{i}(\mathrm{~d})$, shape index (e) and curvedness (f) of 4-CMDHP
Fig. 4. Fingerprint plot analysis with a $d_{\text {norm }}$ for none (a), all..all (100 \%) (b), O...H/H...O (35.7 \%) (c), H...H (27.7\%) (d), $\mathrm{Cl} . . \mathrm{H} / \mathrm{HCl} . . \mathrm{H}(17 \%)(\mathrm{e})$ and H...C/C...H $(10.9 \%)(f)$ contacts in 4-CMDHP

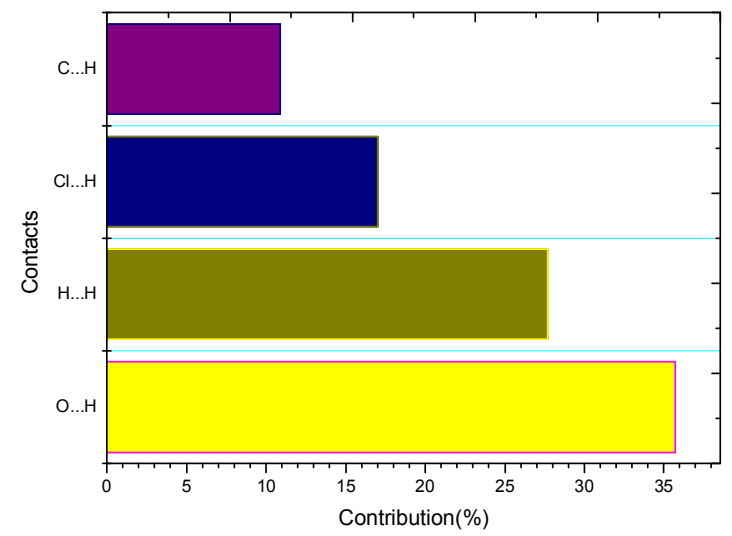

Fig. 5. Relative contributions to the percentage of Hirshfeld surface area for various intermolecular contacts in the title compound 


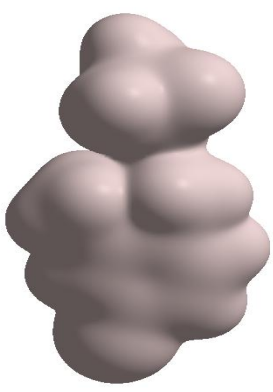

a)

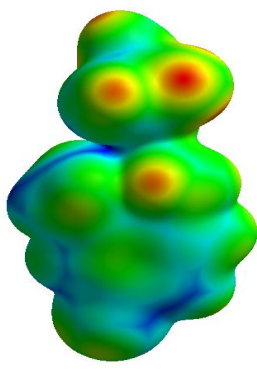

c)

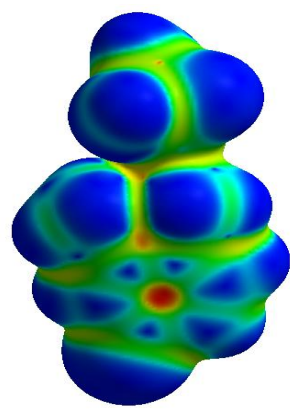

e)

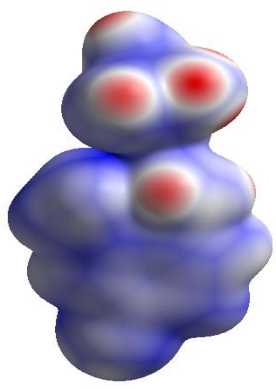

b)

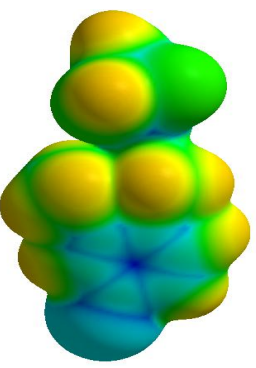

d)

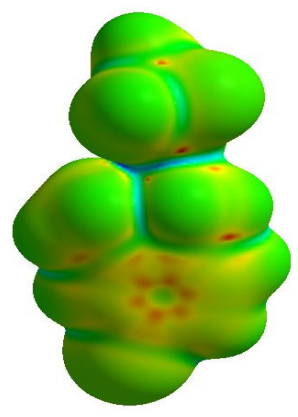

f)
Fig. 6. Electrostatic potential (PE) mapped on Hirshfeld surface of the molecule of 4-CMDHP: Hirshfeld surface (a), $d_{\text {norm }}(\mathrm{b}), d_{e}$ (c), $d_{i}(\mathrm{~d})$, shape index (e) and curvedness (f)

\subsection{Interaction Energies and Energy Frameworks}

The interaction energies between the molecules are obtained using monomer wave functions at the B3LYP/6$31 \mathrm{G}(\mathrm{p}, \mathrm{d})$ level. The total interaction energy, which is the sum of scaled components of Coulomb (a) and dispersion (b) energies, is visualized in the Fig. 7c. The scale factors used in the CE-B3LYP benchmarked energy model [18] are given in Table 1. The energies calculated by the energy model reveal that the dispersion energy contributes significantly to the interactions in the crystal (Table 2).

\subsection{Theoretical Studies}

\subsubsection{Optimized geometry}

The optimized structure of the single crystal. The molecular geometry is calculated by the DFT (PBEPBE/3-21G, B3LYP/3-21G), Hartree-Fock (HF/3$21 \mathrm{G}$ ) and MP2/3-21G levels calculations were carried out to predict the geometry of the title molecule compound. The actual and optimized bond lengths, which were obtained by X-ray crystallographic study as well as by geometry optimizations, are reported in Fig. 8. The optimized molecular structure of 4-CMDHP closely resembles the XRD structure. The calculated bond lengths and angles for 4-CMDHP compared with experimental data are listed in Table 3. The optimized bond lengths of $\mathrm{C}-\mathrm{C}$ in a phenyl ring fall in the range from 1.375 to $1.395 \AA$ for B3LYP/3-21G method, and are in a reliable agreement with experimental values for $\mathrm{C}-\mathrm{C}$ bond length of phenyl ring. Intermolecular interactions connect molecules, resulting in differences of bond parameters between calculated and experimental values (Fig. 9).

a)

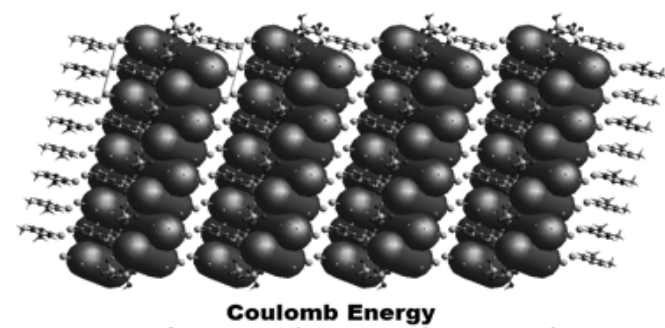

b)

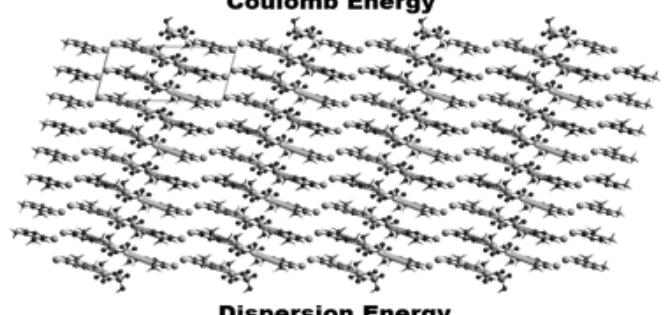

c)

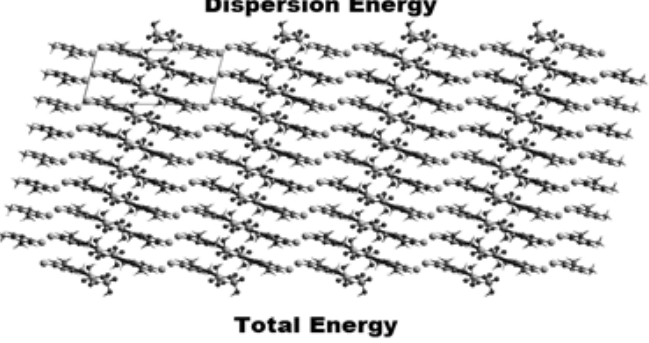

Fig. 7. Energy frameworks of 4-CMDHP representing electrostatic (a), dispersion (b), and total interaction energy terms (c)

Scale factors for benchmarked energy models

\begin{tabular}{|c|c|c|c|c|c|c|}
\hline$R$ & Electron density & $E_{\text {ele }}$ & $E_{\text {pol }}$ & $E_{\text {dis }}$ & $E_{\text {rep }}$ & $E_{\text {tot }}$ \\
\hline 3.36 & B3LYP/6-31G(d,p) & -62.2 & -5.5 & -11.8 & 120.6 & -5.6 \\
\hline
\end{tabular}


Table 2

Interaction energies $(\mathrm{kJ} / \mathrm{mol})$ of the molecular pairs calculated from energy framework calculation of 4-CMDHP

\begin{tabular}{|c|c|c|c|c|}
\hline Energy model & $k_{\text {ele }}$ & $k_{p o l}$ & $k_{\text {dis }}$ & $k_{\text {rep }}$ \\
\hline CE-HF...HF/3-21G electron densities & 1.019 & 0.651 & 0.901 & 0.811 \\
\hline CE-B3LYP...B3LYP/6-31G $(\mathrm{d}, \mathrm{p})$ electron densities & 1.057 & 0.740 & 0.871 & 0.618 \\
\hline
\end{tabular}

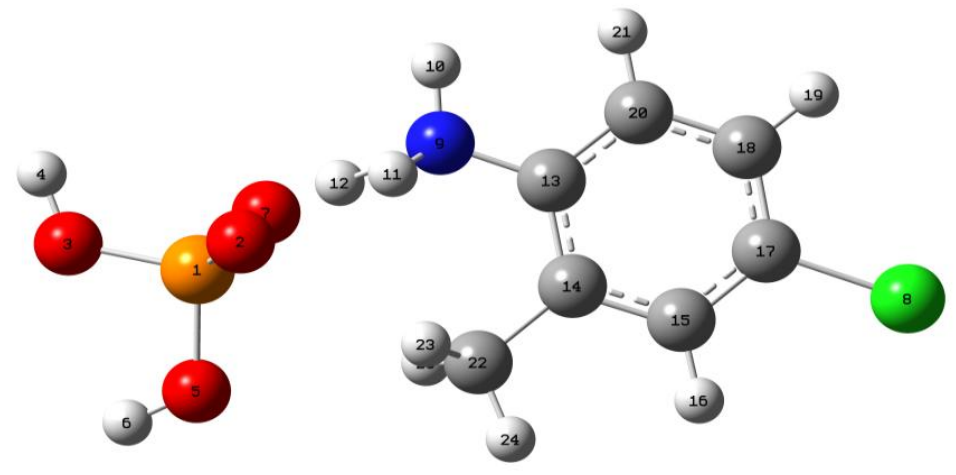

Fig. 8. The optimized structure of 4-CMDHP determined using the DFT/B3LYP method with 3-21G basis set and formed by one independent dihydrogen phosphate $\mathrm{H}_{2} \mathrm{PO}_{4}$ anion (left) and one 4-chloro-2-methylanilinium $\mathrm{C}_{7} \mathrm{H}_{9} \mathrm{ClN}^{+}$cation (right)

Table 3

Optimized geometrical parameters of 4-CMDHP molecules, bond length ( $($ )

\begin{tabular}{|c|c|c|c|c|c|}
\hline Parameters & Expt & DFT/PBEPBE/3-21G & $\mathrm{HF} / 3-21 \mathrm{G}$ & DFT/B3LYP/3-21G & $\mathrm{MP} 2 / 3-21 \mathrm{G}$ \\
\hline $\mathrm{R}(1,2)$ & 1.5042 & 1.5640 & 1.5374 & 1.5497 & 1.5478 \\
\hline $\mathrm{R}(1,3)$ & 1.5639 & 1.7055 & 1.6239 & 1.6771 & 1.6700 \\
\hline $\mathrm{R}(1,4)$ & 1.5599 & 1.7396 & 1.6174 & 1.7024 & 1.6894 \\
\hline $\mathrm{R}(1,6)$ & 1.4935 & 1.6478 & 1.607 & 1.6354 & 1.6373 \\
\hline $\mathrm{R}(3,27)$ & 0.8201 & 1.0048 & 0.9638 & 0.9928 & 0.9883 \\
\hline $\mathrm{R}(4,5)$ & 0.8197 & 1.0061 & 0.9661 & 0.9933 & 0.9901 \\
\hline $\mathrm{R}(6,7)$ & 1.8750 & 1.1592 & 1.0022 & 1.0876 & 1.0542 \\
\hline $\mathrm{R}(8,20)$ & 1.7329 & 1.8301 & 1.8189 & 1.8328 & 1.8457 \\
\hline $\mathrm{R}(9,13)$ & 0.8905 & 1.0346 & 1.0055 & 1.0246 & 1.0253 \\
\hline $\mathrm{R}(9,25)$ & 0.8897 & 1.0627 & 1.0147 & 1.0385 & 1.0324 \\
\hline $\mathrm{R}(9,26)$ & 0.8903 & 1.4230 & 1.7719 & 1.5349 & 1.6289 \\
\hline $\mathrm{R}(9,27)$ & 1.4496 & 1.448 & 1.4252 & 1.4410 & 1.4518 \\
\hline $\mathrm{R}(10,11)$ & 1.3796 & 1.4186 & 1.3970 & 1.4104 & 1.4164 \\
\hline $\mathrm{R}(10,18)$ & 1.3766 & 1.4054 & 1.3854 & 1.3977 & 1.4061 \\
\hline $\mathrm{R}(10,20)$ & 1.3942 & 1.4066 & 1.3840 & 1.3983 & 1.4061 \\
\hline $\mathrm{R}(11,12)$ & 1.5253 & 1.5159 & 1.5150 & 1.5152 & 1.5254 \\
\hline $\mathrm{R}(11,13)$ & 0.9308 & 1.0915 & 1.0701 & 1.0822 & 1.0864 \\
\hline $\mathrm{R}(13,14)$ & 1.3758 & 1.3952 & 1.3740 & 1.3869 & 1.3959 \\
\hline $\mathrm{R}(14,15)$ & 1.3608 & 1.3930 & 1.3688 & 1.3840 & 1.3930 \\
\hline$R(14,16)$ & 0.9299 & 1.0902 & 1.0694 & 1.0812 & 1.0848 \\
\hline $\mathrm{R}(16,17)$ & 1.3835 & 1.4031 & 1.3829 & 1.3954 & 1.4055 \\
\hline $\mathrm{R}(16,18)$ & 0.9294 & 1.0938 & 1.0722 & 1.0845 & 1.0885 \\
\hline $\mathrm{R}(18,19)$ & 0.9605 & 1.1057 & 1.0829 & 1.0964 & 1.0958 \\
\hline $\mathrm{R}(20,21)$ & 0.9599 & 1.1010 & 1.0818 & 1.0925 & 1.0943 \\
\hline $\mathrm{R}(21,22)$ & 0.9598 & 1.1053 & 1.0847 & 1.0953 & 1.0939 \\
\hline
\end{tabular}



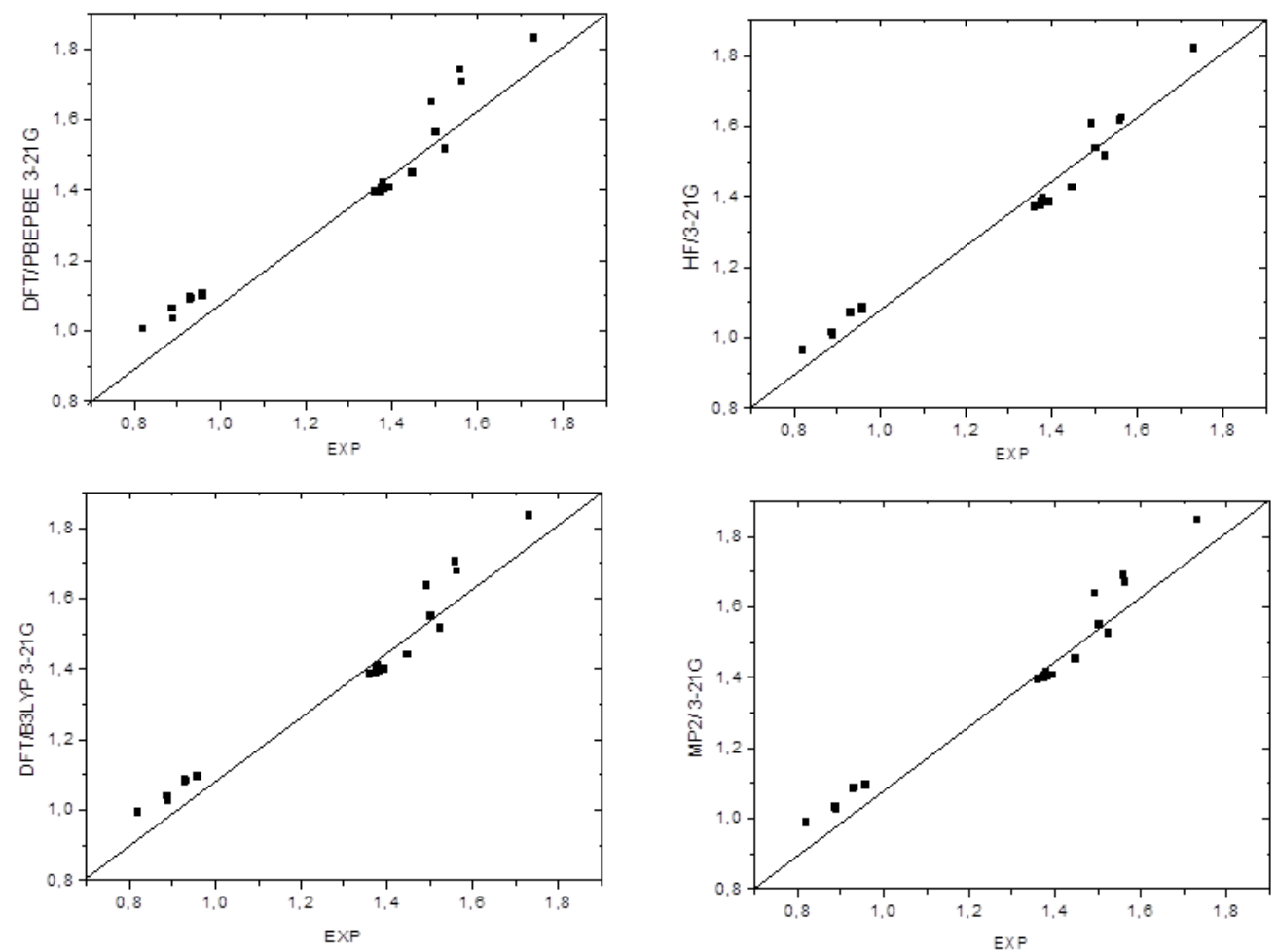

Fig. 9. Linear fitting of experimental and theoretical data of bond length

\subsubsection{Molecular electrostatic potential analysis}

Molecular electrostatic potential (MEP) mapping was recently used for the investigation of the relationships between molecular structure and physico-chemical properties [19-21]. To predict reactive sites for an electrophilic and nucleophilic attack on the 4-CMDHP molecule, MEP was calculated at the HF/3-21G level of the optimized geometry using Gaussian 03W [22, 23]. The analysis of the MEP surface represents charge distribution on the molecular surface. Based on the colored region of the surface the chemical reactive sites were identified. The positive regions (blue) of MEP represent the electrophilic reactivity, the negative regions (green) are related to nucleophilic reactivity of the molecule, and the red regions are related to the electrophilic attack. MEP shows that the negative regions are concentrated around the oxygen atoms and the blue regions are spread around the hydrogen atoms attached to carbon atoms (Figs. 10, 11). These results confirm those ones obtained by the Hirshfeld surface analysis.

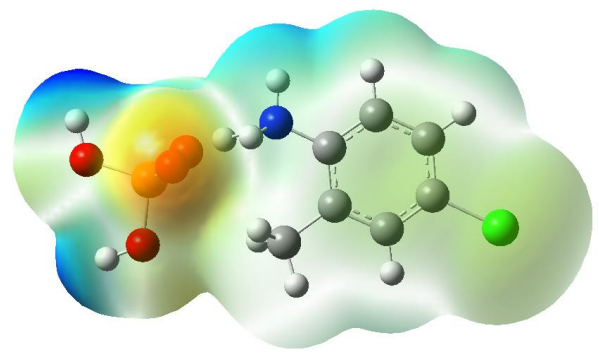

Fig. 10. Molecular electrostatic potential, mapping of the title compound

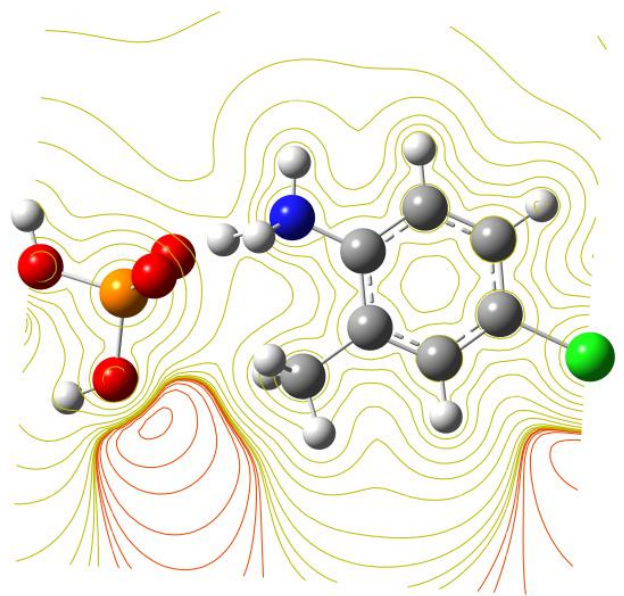

Fig. 11. Molecular structure of 4-CMDHP. Contour map 


\subsubsection{HOMO-LUMO analysis}

The frontier molecular orbitals defining the way of 4-CMDHP molecule interact with other entities and help to determine their kinetic stability and chemical reactivity. HOMO-LUMO orbitals were computed for the organicinorganic molecule by the DFT/B3LYP/3-21G method. These calculations were made with the Gaussian 03 program and the results are displayed in Fig. 12. According to the molecular orbital theory due to interactions between HOMO-LUMO, $\pi-\pi^{*}$ transitions are observed in transition states [24]. While HOMO energy is related to the ionization potential, LUMO energy is related to the electron activation. Additionally, as the HOMO energy level increases, the inhibitory property increases too. The energy difference between HOMO and LUMO is called an energy band gap $\left(\Delta E=E_{\mathrm{LUMO}}-E_{\mathrm{HOMO}}\right)$. It is an important parameter for the stability of the structures. The highest occupied molecular orbital (HOMO) is located mainly on the aromatic ring and on the nitrogen atom which is linked to it with a calculated energy, and the LUMO is concentrated on the $\mathrm{NH}_{2}$ group with a calculated energy. The large energy gap between the HOMO and LUMO orbitals $(4.249 \mathrm{eV})$ shows that the molecule is kinetically stable and has a small chemical reactivity [2528]. The energy distributions of the difference are given in Fig. 12 and are also quite similar in three cases, showing that there is no high constraint in the crystal.
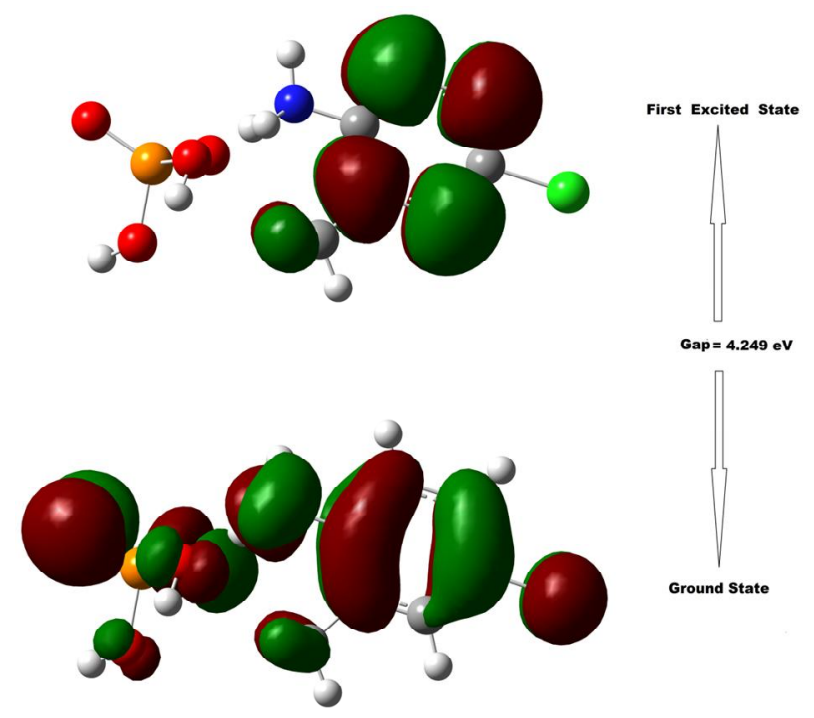

Fig. 12. Graphical representation of frontier molecular orbital of the 4-CMDHP. HOMO: highest occupied molecular orbital; LOMO: lowest unoccupied molecule

\subsubsection{Global and local reactivity descriptors}

The energy gap between HOMO and LUMO is an important parameter to calculated molecular electrical transport properties. The global chemical reactivity descriptors of molecules such as hardness, chemical potential, softness, electronegativity and electrophilicity index can be determined using following expressions [2933]:

Electron affinity $\left(A=-E_{\mathrm{LUMO}}\right)$ can be expressed through HOMO and LUMO orbitals. The electrophilicity index $\omega$ (Eq. (2)) is a measure of energy lowering due to the maximum electron flow between the donor and the acceptor:

$$
\omega=\frac{\mu^{2}}{2 \eta}
$$

where $\omega$ is the electrophilicity index; $\mu$ is the chemical potential; $\eta$ is the chemical hardness.

The calculated values of chemical hardness $(\eta)$, softness $(S)$, chemical potential $(\mu)$, electronegativity $(\chi)$ and global electrophilicity index $(\omega)$ are given in Table 4.

Table 4

HOMO-LUMO energy gap and related molecular properties of 4-CMDHP molecule

\begin{tabular}{|c|c|}
\hline Molecular properties & B3LYP/3-21G \\
\hline HOMO energy & -0.20638 a.u. \\
LUMO energy & -0.04975 a.u. \\
HOMO-LUMO energy gap & $4.249 \mathrm{eV}$ \\
Ionization potential $(I)$ & 0.20638 a.u. \\
Electron affinity $(A)$ & 0.04975 a.u. \\
Chemical hardness $(\eta)$ & 0.07831 a.u. \\
Chemical potential $(\mu)$ & -0.12806 a.u. \\
Electronegativity $(\chi)$ & 0.12806 a.u. \\
Global softness $(S)$ & 0.03915 a.u. ${ }^{-1}$ \\
Global electrophilicity index $(\square)$ & $2.838 \mathrm{eV}$ \\
\hline
\end{tabular}

\subsubsection{Density of states (DOS)}

Adjoining orbitals may show quasi-degenerate energy levels in the boundary region. In such cases, consideration of only the HOMO and LUMO may not yield a realistic description of the frontier orbitals. For this reason, total density-of-states (TDOS), partial density-ofstates (PDOS) and overlap population density-of-states (OPDOS) or COOP (crystal orbital overlap population) density of states are needed [34]. The most important application of the DOS plots is to locate molecular orbital compositions and their contributions to the chemical bonding through the OPDOS plots which are also referred in the literature as the crystal orbital overlap population (COOP) diagrams. The calculated TDOS diagram of 4-CMDHP is shown in Fig. 13. The (2) and (3) lines of the TDOS spectrum indicate the occupied orbital and virtual orbital levels, respectively. The PDOS plots show the composition of the fragment orbitals contributing to the molecular orbitals. The OPDOS shows the bonding, anti-bonding and nonbonding nature of the interaction of 
the two orbitals, atoms or groups. A positive value of the OPDOS indicates a bonding interaction, a negative value shows that there is an anti-bonding interaction and zero value indicates nonbonding interactions [35-39]. $\mathrm{H}$ with $\mathrm{C}$ (line (1)) is highly overlapped orbital as compared with other overlapped $(\mathrm{N}, \mathrm{Cl}$, and $\mathrm{O}$ ) orbitals. $\mathrm{O}$ with $\mathrm{N}$ (line (2)) is lowly overlapped orbital compared with other overlapped (H, C and O) orbitals. The OPDOS plots have anti-bonding character in frontier (HOMO and LUMO) molecular orbitals for benzene ring and oxygen atoms. Also, OPDOS showed a bonding character for both HOMO and LUMO.

(1)

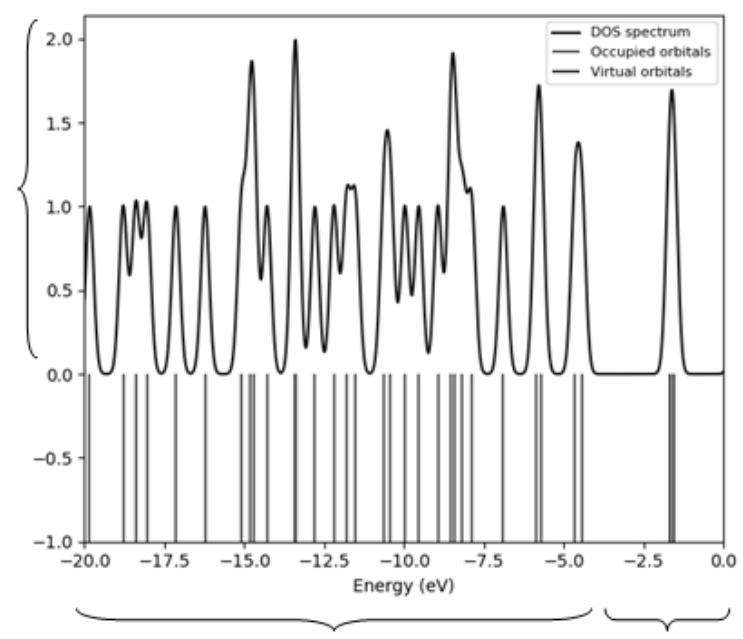

(2)

(3)

Fig. 13. The density of states (DOS) diagram of 4-CMDHPmolecule

\subsubsection{Charge distribution}

The atomic charge calculation plays an important role in the application of quantum chemical calculation to molecular system because atomic charges affect many properties such as electronic structure, dipole moment, molecular polarizability and so on [40, 41]. Mulliken atomic charge distribution of 4-CMDHP molecule is shown in Fig. 14. The charge distribution of the 4-CMDHP molecule shows that the magnitude of atomic charges of the individual atoms was ranging from $-0,720$ to 1.201 and color code region -1.000 (red) to 1.000 (green), respectively, the plots of atomic charges and Mulliken charges with hydrogen summed into heavy atoms, respectively. The Mulliken charges with hydrogen summed into heavy atoms were ranging from -0.20510 to 0.49522 . The atomic charge analysis shows that the maximum negative and positive atomic charges were obtained for (O7) and (N9), respectively. All the hydrogen atoms have positive charges. The charge transfer occurs from hydrogen to carbon atom. Only one carbon atom (C18) has a positive charge, the remaining ones have negative charges. The sum of Mulliken atomic charges of the atoms and Mulliken charges with hydrogen summed into heavy atoms of the 4-CMDHP molecule become zero and thus maintain the charge neutrality.

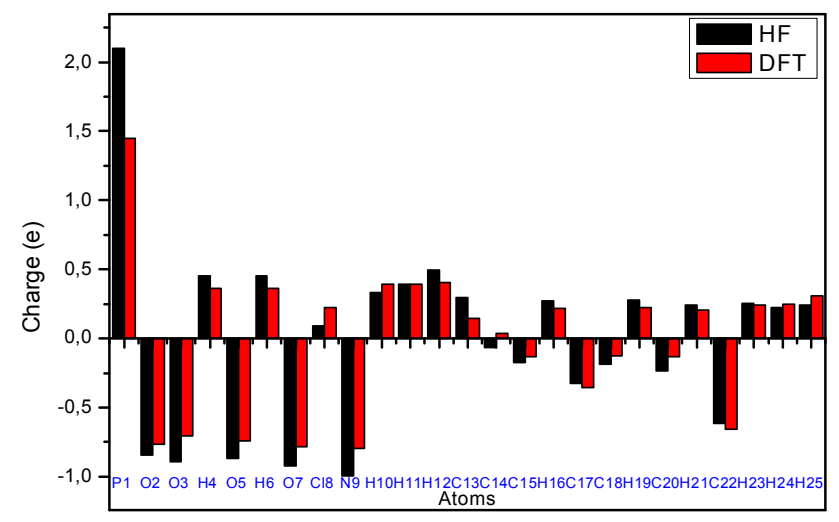

Fig. 14. The atomic charge distribution of the 4-CMDHP

\section{Conclusions}

In summary, the structure consists of alternation of organic and inorganic layers. Comparison of bond length of theoretical and experimental values shows slight variations. Hydrogen bonding interactions were quantified using fingerprint and Hirshfeld surface analysis. The supramolecular architecture of the title compound is stabilized by intermolecular hydrogen bonding interactions. Most of the atomic charges are matched with the natural atomic charges. Minor differences in the natural and Mulliken atomic charges are noted. The MEP surface indicated the positive and negative potential areas originated in the $\mathrm{N}-\mathrm{H}$ hydrogen atoms and oxygen atoms, respectively. Finally, the DFT calculations unravel that the HOMO profiles are located on the nitrates, but the LUMOs are located on the 4-CMDHP ligand for the studied complexes. They also show that the energy gaps between the HOMO and LUMO decrease upon coordination of 4-CMDHP. It can be concluded from the molecular orbital energy calculations that the molecule has a wide HOMO-LUMO range and consequently the structure exhibits stable and low chemical reactivity.

\section{Acknowledgements}

The author thanks the Centre for Analysis and Research of the Ibn Tofail University, Morocco.

\section{References}

[1] Judeinstein P., Sanchez C.: J. Mater. Chem, 1996, 6, 511. https://doi.org/10.1039/JM9960600511 
[2] Adhikari S., Kar T., Seth S.: RSC Adv., 2016, 6, 99139. https://doi.org/10.1039/C6RA21466E

[3] Lehn J.-M.: Supramolecular Chemistry, $1^{\text {st }}$ edn. Wiley-VCH, New York 1995. https://doi.org/10.1002/3527607439

[4] Etter M., Frankenbach G.: Chem. Matter., 1989, 1, 10. https://doi.org/10.1021/cm00001a005

[5] Vishweshwar P., McMahon J., Bis J., Zaworotko M.: J. Pharm. Sci., 2006, 95, 499. https://doi.org/10.1002/jps.20578

[6] Frisch M., Trucks G., Schlegel H. et al.: Gaussian 03, Gaussian, Inc. Wallingford CT, 2004.

[7] Dennington R., Keith T., Millam J.: Gauss View, Version 5, Semichem, Shawnee Mission KS, 2009.

[8] Clementi E., RoettiC.: Atom. Data Nucl. Data, 1974, 14, 177. https://doi.org/10.1016/S0092-640X(74)80016-1

[9] SpackmanM., Jayatilaka D.: Cryst. Eng. Comm., 2009, 11, 19. https://doi.org/10.1039/B818330A

[10] Spackman M.: Phys. Scr., 2013, 87, 048103.

https://doi.org/10.1088/0031-8949/87/04/048103

[11] Turner M., McKinnon J., Jayatilaka D., Spackman M.: Cryst.

Eng. Comm., 2011, 13, 1804. https://doi.org/10.1039/C0CE00683A

[12] McKinnon J., Jayatilaka D., Spackman M.: Chem. Commun., 2007, 161, 3814. https://doi.org/10.1039/b704980c

[13] Spackman M., McKinnon J., Jayatilaka D.: Cryst. Eng. Comm., 2008, 10, 377. https://doi.org/10.1039/B715227B

[14] Hirshfeld F.: Theor. Chim. Acta, 1977, 44, 129.

https://doi.org/10.1007/BF00549096

[15] Luo Y., Mao Q., Sun B.: Inorg. Chim. Acta, 2014, 412, 60.

https://doi.org/10.1016/j.ica.2013.12.005

[16] Luo Y., Sun B.: Cryst. Growth. Des., 2013, 13, 2098.

https://doi.org/10.1021/cg400167w

[17] Desiraju G., Gavezzotti A.: Acta Crystallogr. B, 1989, 45, 473. https://doi.org/10.1107/S0108768189003794

[18] Wolff S., Grimwood D., McKinnon J. et al.: Crystal Explorer

3.1, University of Western Australia, Perth 2012.

[19] Scrocco E., Tomasi J.: Top. Curr. Chem., 1973, 42, 95.

https://doi.org/10.1007/3-540-06399-4_6

[20] Lipkowitz K., Boyd D. (Eds.): Reviews in Computational

Chemistry, vol. 2. Wiley-VCM, New York 1991.

https://doi.org/10.1002/9780470125793

[21] Naray-Szabo G., Ferenczy G.: Chem. Rev.,1995, 95, 829.

https://doi.org/10.1021/cr00036a002

[22] Jamroz M., Dobrowolski J., Brzozowski R.: J. Mol. Struct.,

2006, 787, 172. https://doi.org/10.1016/j.molstruc.2005.10.044

[23] Bellamy L.: The infrared Spectra of Complex Molecules, vol.

$2,2^{\text {nd }}$ edn. Chapman and Hall, London 1990.

[24] Fukui K.: Science, 1982, 218, 747.

https://doi.org/10.1126/science.218.4574.747

[25] Buyukuslu H., Akdogan M., Yildirim G., Parlak C.:

Spectrochim. Acta A, 2010, 75, 1362.

https://doi.org/10.1016/j.saa.2010.01.003

[26] Parr R., Donnelly R., Levy M., Palke W.: J. Chem. Phys., 1978, 68, 3801. https://doi.org/10.1063/1.436185

[27] Parr R., Pearson R.: J. Am. Chem. Soc., 1983, 105, 7512.

https://doi.org/10.1021/ja00364a005
[28] Parr R., Szentpaly L., Liu S.: J. Am. Chem. Soc., 1999, 121, 1922. https://doi.org/10.1021/ja983494x

[29] Saeidian H., Sahandi M.: J. Mol. Struct., 2015, 1100, 486. https://doi.org/10.1016/j.molstruc.2015.07.069

[30] Gokçe H., Bahçeli S.: Spectrochim. Acta A, 2013, 114, 61. https://doi.org/10.1016/j.saa.2013.04.112

[31] Kohn W., Becke A., Parr R.: J. Phys. Chem., 1996, 100, 12974. https://doi.org/10.1021/jp9606691

[32] Seth S.K., Banerjee S., Kar T.: J. Mol. Struct., 2010, 965, 45. https://doi.org/10.1016/j.molstruc.2009.11.036

[33] Pearson R.: Proc. Natl. Acad. Sci. USA, 1986, 83, 8440. https://doi.org/10.1073/pnas.83.22.8440

[34] Mulliken R.: J. Chem. Phys., 1955, 23, 1833. https://doi.org/10.1063/1.1740588

[35] Hoffmann R.: Solids and Surfaces: A Chemist's View of Bonding in Extended Structures. VCH Publ., New York 1988. [36] Hughbanks T., Hoffmann R.: J. Am. Chem. Soc., 1983, 105, 3528. https://doi.org/10.1021/ja00349a027

[37] Małecki J.: Polyhedron, 2010, 29, 1973.

https://doi.org/10.1016/j.poly.2010.03.015

[38] O'Boyle N., Tenderholt A., Langner K.: J. Comp. Chem., 2008, 29, 839. https://doi.org/10.1002/jcc.20823

[39] Chen M., Waghmare U., Friend C., Kaxiras E.: J. Chem. Phys., 1998, 109, 6854. https://doi.org/10.1063/1.477252

[40] Mulliken R.: J. Am. Chem. Soc., 1952, 74, 811. https://doi.org/10.1021/ja01123a067

[41] Mulliken R.: J. Chem. Phys., 1955, 23, 1833.

https://doi.org/10.1063/1.1740588

Received: June 13, 2019 / Revised: July 16, 2019 / Accepted: December 04, 2019

\section{ЛІНІЙНИЙ N-Н...О ВОДНЕВИЙ ЗВ‘ЯЗОК У \\ ГІБРИДНОМУ ФОСФАТІ: МЕТОД ПОВЕРХНІ ГІРШВЕЛЬДА I DFТ КВАНТОВІ ХІМІЧНІ РОЗРАХУНКИ}

\begin{abstract}
Анотація. За допомогою методу поверхні Гіршвельда встановлено, що 3D-надмолекулярна сітка стабілізується $\mathrm{N}-\mathrm{H} \ldots \mathrm{O}$ і $\mathrm{O}-\mathrm{H} \ldots \mathrm{O}$ водневими зв'язками та взаємодіями $\mathrm{O} \ldots \mathrm{N}$, що включають органічний катіон та неорганічний аніон. Показано, щчо Ван-дер-Ваальсовські сили відіграють ключову роль у консолідачії упаковки структури 4-хлор-2-метиланілін дигідрогенфосфату [4-CMDHP]. Для підтвердження ексnериментальних результатів проведені розрахунки за допомогою теорії функиіональної щілльності з використанням функиіоналу B3LYP з базовим набором 3-21 G. Отримані теоретичні результати повністю узгоджуються з експериментальними. Для дослідження нелінійної оптичної поведінки 4-CMDHР визначені поверхня Гіршфельда, шільність та енергетичні зазори НОМO-LUMO. Змодельована поверхня молекулярного електростатичного потениіалу молекули 4-CMDHP.
\end{abstract}

Ключові слова: заборонена зона, діаграма відбитків, поверхня Гіршфельда, гібрид. 